\title{
Creating, Exhibiting and Distributing New Media for Historic Fashion
}

\author{
The Drexel Digital Museum Project
}

\author{
Kathi Martin \\ Drexel University USA \\ martink@drexel.edu \\ Daniel Caulfield-Sriklad \\ London College UK \\ danielsriklad@gmail.com
}

Nick Jushchyshyn

Drexel University USA

nej29@drexel.edu

\begin{abstract}
An international, interdisciplinary group of fashion historians and makers, informatics and metadata specialists, and digital media experts from Drexel University, Seoul National University, the University of New South Wales, Australia, the Fulbright Foundation and the Controlled Vocabulary Working Group of the Costume Society of America are researching production and conservation of new media for exhibition of historic fashion. Our team has created prototype 3D interactive media that will allow the viewer to be an active participant in the exhibition of historic fashion. Rich metadata descriptions of these media ensure their persistent discovery, access and conservation.
\end{abstract}

Keywords: Digital media; Cultural heritage; Historic fashion; ObjectVR; Collaborative research

\section{The Drexel Digital Museum Project}

Driven by a complex set of motivations, ranging from civic duty and personal recognition, to the transfer of the homogeneous values of America's elite to the country's broad, mostly immigrant underclass, A. J. Drexel founded The Drexel Institute of Art, Science, and Industry (Rottenberg, 2006). Being the son of American artist Francis Martin Drexel and understanding the influence and inspiration of both fine and design arts side by side with the study of science and industry in preparing young men and women for the industrial age, Drexel directed the purchase of design and fine art from the many world exhibitions of the time and the Drexel Collection was born. When Drexel opened its doors in 1892 the Drexel Collection, including textiles and nonwestern dress, was on display in vitrines on the first floor of the Institute to inspire the students and the visiting public. In the 1920s, European and American dress were added. The Drexel Historic Costume Collection, now the Robert and Penny Fox Collection (FHCC), has continued to grow to a current estimated 1400+ fashion objects and to be one of the finest fashion teaching collections in the United States.

A. J. Drexel's vision for a learning environment that would be a confluence of art, science and industry continues in the Drexel Digital Museum project (DDM) which was begun in 1999 as an image archive of selections from the FHCC, and the private collections of noted international style icon Iris Barrel Apfel (Sylvia, 2016) and influential Philadelphia fashion retailor Toby Lerner (Wellington, 2007). Our mission is to provide open access to fashion design collections and exhibitions for scholarly research and enjoyment by the general public. Online, users can search the DDM archive and interact with high quality 3D interactive fashion images. Or they may meander through galleries of fashion exhibitions held in the Pearlstein Gallery of the Antoinette Westphal College, Drexel, and other galleries born digital from contributions of fashion ephemera (Figure 1).
Figure 1. Drexel Digital Museum Project. Gallery screen. http://digimuse.westphal.drexel.edu .

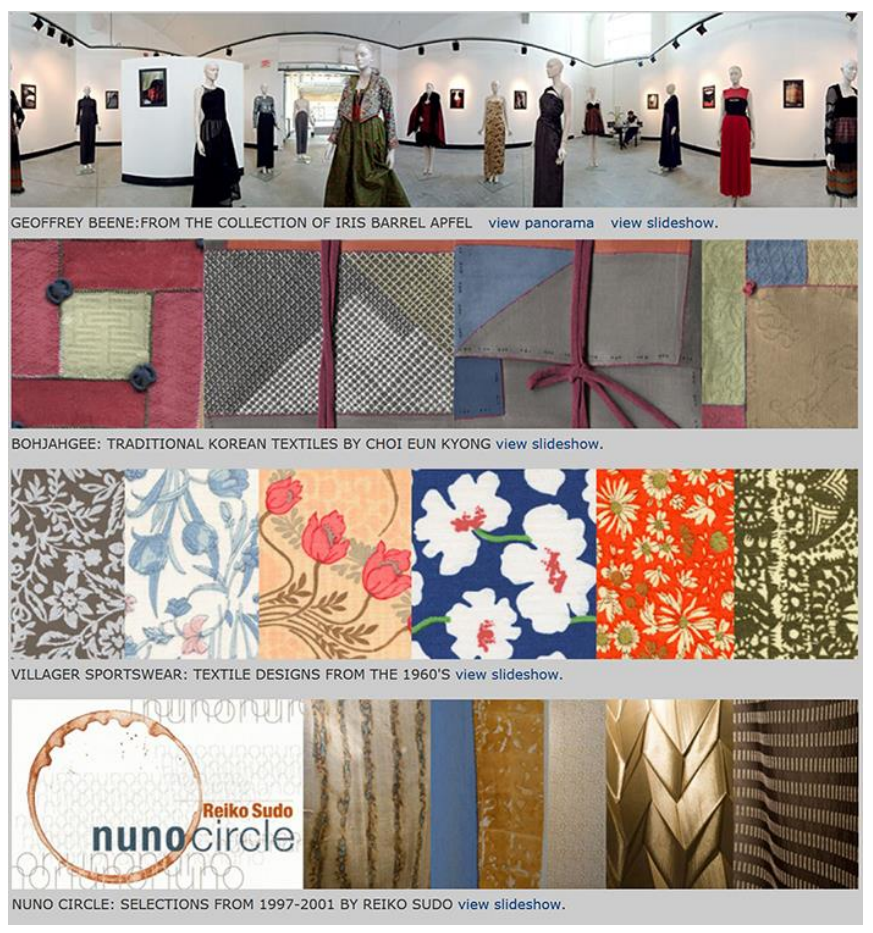

\section{Imaging Fashion}

"Images provide narratives of a culture, clues and revelations of the way a social group, or indeed a nation, envisions itself, particular to time and space (Arnold, 2002, p.45)." Dressing is always picture making (Hollander, 1973). Historic twodimensional representations infer fashion, whether on a notable personage in dress, such as actor Ellen Terry as 
SIGraDi 2016, XX Congress of the Iberoamerican Society of Digital Graphics

9-11, November, 2016 - Buenos Aires, Argentina

Lady Macbeth, wearing her famous beetle wing dress, in the John Singer Sargent portrait in figure 2; or in the undress of a more common social stratum, as in the $4^{\text {th }}$ century Roman mosaic in figure 3 .

Figure 2. Left: John Singer Sargent, Ellen Terry as Lady Macbeth, 1888, oil on canvas, $221.0 \times 114.3 \mathrm{~cm}$. Collection:Tate. Right: The Beetle Dress, designed by Alice-Comyns-Carr and constructed by Ada Nettleship. Collection: Ellen Terry Museum, Smallhythe Place. Retrieved from: deborahklein.blogspot.com.
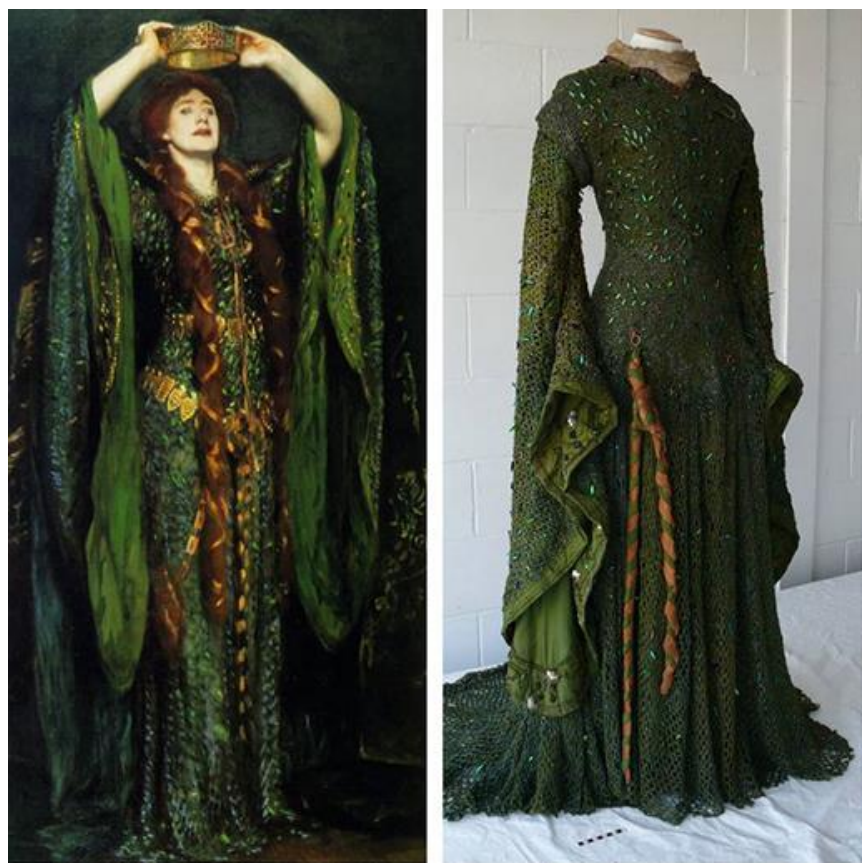

Figure 3. Fourth-century AD mosaic from Villa del Casale, Sicily, depicting prostitute with a client. Image courtesy of (VRoma, Barbara McManus) Retrieved from: http://www.the-romans.co.uk/women.htm

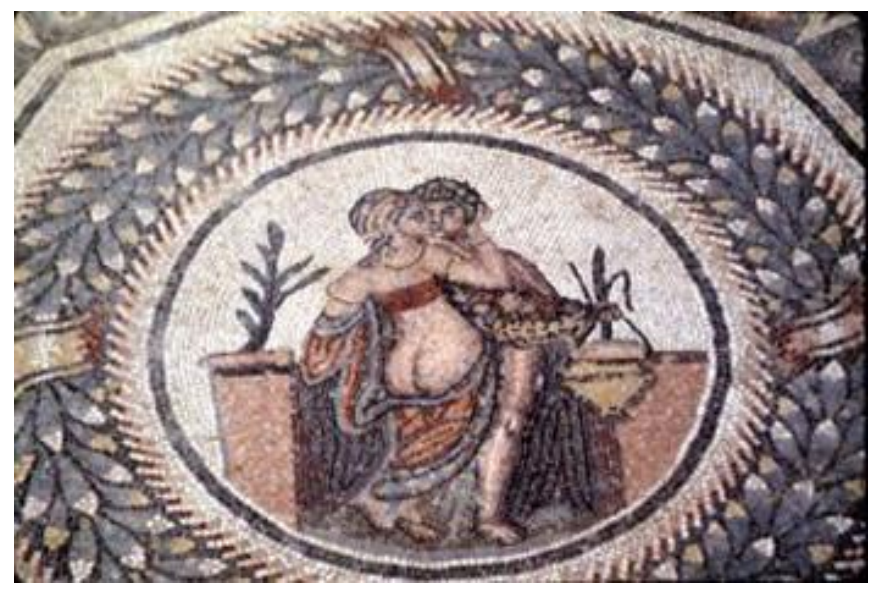

Fashion is an aspect of visual culture involving form, color, and texture, all of which can be realistically captured two dimensionally. The Ellen Terry portrait is an excellent example of Sargent's exquisite rendering of fabrics, particularly their vibrant colors, textures and patterns. The original green-silk and blue-tinsel dress, which is sewn with a multitude of iridescent beetle wings and with a border of Celtic design, was designed by Alice Comyns Carr, who was a close friend of Sargent. The gown was restored through the National Trust of the United Kingdom for $£ 110,000$ and now resides in the collection of Terry's theatrical costumes at Smallhythe Place in Kent, her last home (Kennedy, 2011).

Adam Lowe, one of the founders of the high resolution imaging company Factum Arte, argues that "...facsimiles, and especially those relying on complex (digital) techniques, are the most fruitful way to explore the original and even to help re-define what originality actually is." And that "The digital is just one instance in the life of the original object" (Sattin, Lowe, 2014). With his facile expertise in capturing texture, color and the effect of light on fabric via brushwork, Sargent creates a dynamic second instance of the original object and an object in its own right. In figure 2, we can compare Sargent's portrait, retrieved and reproduced from a screen grab of the Tate's digital surrogate, distributed via Deborah Klein's blog and now published in this paper, to the original gown, creating three additional instances of Carr's design and two for Sargent's artwork.

Lowe recommends creating digital images of artwork at "... the highest possible resolutions and archive them in raw formats, so the data can continue to be re-processed as technology advances" (Sattin, Lowe, 2015). When the DDM began in 1999, most museums were struggling to protect unofficial repurposing of any images of their holdings they put online. Watermarking the image with the museum's name prevented direct copying of the image to t-shirts and tote bags. The DDM decided to image and to display the best quality images possible, no watermarking, as a way to increase visibility and relevance of the FHCC which at the time had a very local audience, limited to faculty and students and an occasional loan to an exhibition. Using QuickTime Virtual Reality (QTVR) to create panoramic movies of each garment for the DDM archive allowed for the viewer to interact with the QTVR, choose any of the eighteen views in the panorama and see close up details of construction and embellishment, creating their own exhibition experience. Rather than use the available zoom technology, we embedded the detail images as hotspots in the QTVR .mov file.

Figure 4. A comparison chart of the standards of the Drexel Digital Museum project and the National Archive.

\begin{tabular}{|l|l|l|l|}
\hline \multicolumn{4}{|c|}{ A Comparison of Archival Data and Image Standards National Archive-Drexel Digital Museum Project } \\
\hline & Current NARA Standards & DDM Standards 2000-2014 & DDM Standards 2015 \\
\hline image parameter & $10-16$ megapixel & 6 megapixel & 126.5 megapixel \\
\hline image mode & 24 bit RGB & 24 bit RGB & 24 bit RGB \\
\hline pixel array & $4800 \times 3700$ pixels & $4500 \times 3000$ pixels & $8831 \times 14325$ \\
\hline $\begin{array}{l}\text { alternative image } \\
\text { parameter }\end{array}$ & 6 megapixel & 6 megapixel & N/A \\
\hline alternative pixel array & $4000 \times 3000$ pixels & $4500 \times 3000$ pixels & N/A \\
\hline file formats & JPEG, uncompressed TIFF & JPEG, uncompressed TIFF & JPEG, uncompressed TIFF \\
\hline color profile & custom ICC & MOAC standard & MOAC standard \\
\hline $\begin{array}{l}\text { noise (other objects } \\
\text { or patterns in } \\
\text { backaround) }\end{array}$ & minimal noise & $\begin{array}{l}\text { no noise, grey photopaper } \\
\text { background }\end{array}$ & $\begin{array}{l}\text { no noise, grey photopaper } \\
\text { background }\end{array}$ \\
\hline zoom & no zoom technology & $\begin{array}{l}\text { no zoom technology, individual } \\
\text { close-up files }\end{array}$ & $\begin{array}{l}\text { high resolution detail at 100\% } \\
\text { zoom }\end{array}$ \\
\hline $\begin{array}{l}\text { future file processing } \\
\text { options }\end{array}$ & $\begin{array}{l}\text { files stored direct from } \\
\text { camera, minimal } \\
\text { processing }\end{array}$ & $\begin{array}{l}\text { RAW files stored direct from } \\
\text { camera, TIFF }\end{array}$ & $\begin{array}{l}\text { RAW files stored direct from } \\
\text { camera, TIFF, HTML5 object } \\
\text { panorama }\end{array}$ \\
\hline header data & $\begin{array}{l}\text { camera header data tags } \\
\text { saved }\end{array}$ & $\begin{array}{l}\text { camera header data tags } \\
\text { saved }\end{array}$ & $\begin{array}{l}\text { camera header data tags } \\
\text { saved }\end{array}$ \\
\hline image stitching & $\begin{array}{l}\text { source files and stitched } \\
\text { files saved }\end{array}$ & $\begin{array}{l}\text { source files and stitched files } \\
\text { saved }\end{array}$ & $\begin{array}{l}\text { source files and stitched files } \\
\text { saved }\end{array}$ \\
\hline
\end{tabular}

This proved to be a good decision for continued image standards as evidenced in the chart in figure 4 comparing 
DDM standards to those recommended by the National Archive.

Figure 5. Evening gown. Geoffrey Beene, circa 1970. Collection, Object: Iris Barrel Apfel. Collection, Image: Drexel Digital Museum.
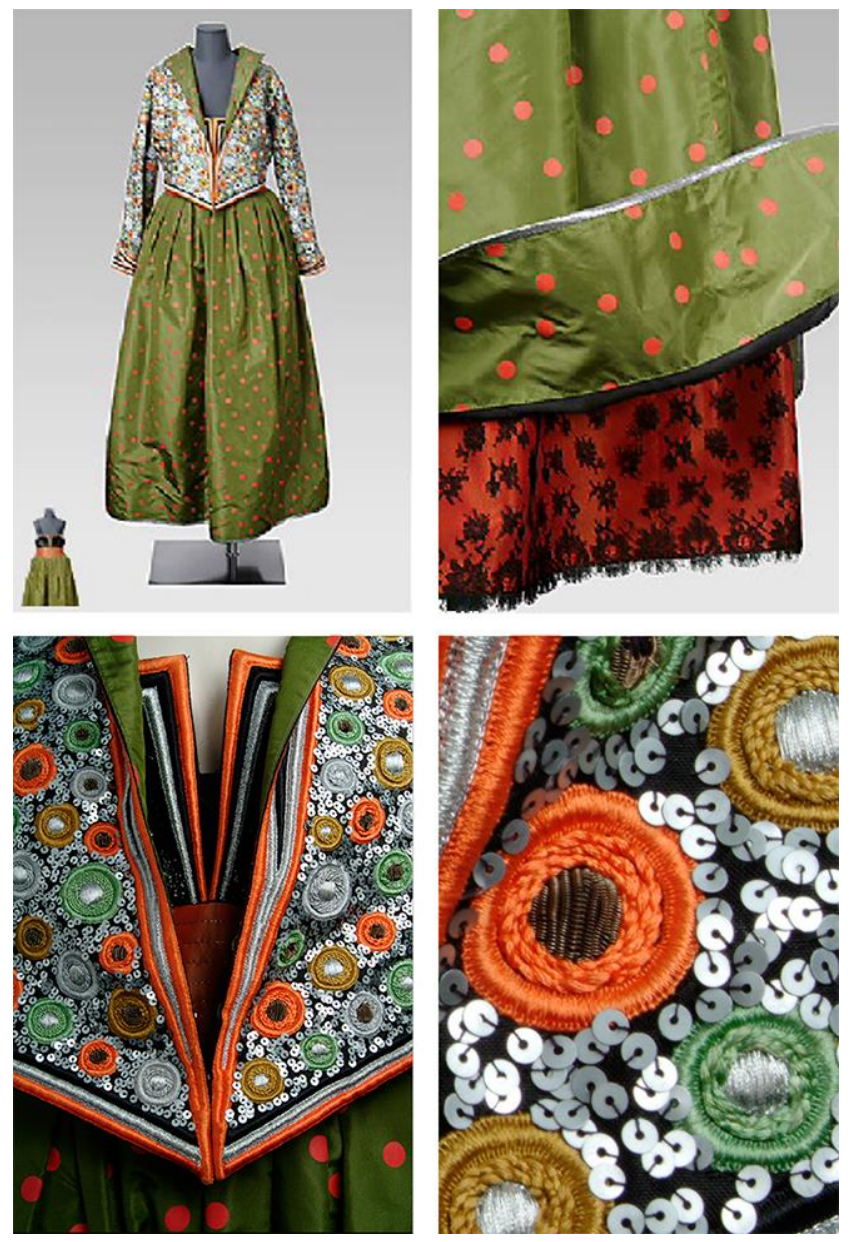

In the QTVR of the gown by Geoffrey Beene detailed in figure 5 , the viewer can remove the jacket, lift the skirt to see the petticoat, and get a close look at the embroidered medallions and paillettes of the jacket.

\section{Distributing Fashion Images via the Crowd}

In 2011, Europeana, a digital platform for collections of cultural heritage of the European Union, issued a white paper on the problems of fidelity with online reproduction of works of art. The Rijksmuseum discovered visitors to the museum did not believe the color on the museum's reproduction post card of Johannes Vermeer's 'The Milkmaid' because the 10,000 unauthorized copies of the artwork online were of such poor quality the colors appeared yellowed. Hence the problem became known as "Yellow Milkmaid's Syndrome." The museum decided that their best defense was to put the best quality image online with open metadata, in the "belief that openness brings benefits both to the cultural heritage sector and to the broader knowledge economy" (Europeana, 2011 , p. 20). Although there are, for most museums, still concerns over proper attribution, loss of income and unauthorized derivative works, this new agreement has led the way for a more open license: Creative Commons CCO. This is a no rights reserved license with a universal public domain dedication. It allows for the re-use of descriptive metadata by others to freely build upon, enhance and reuse the works for any purposes without restriction under copyright or database law, including in a commercial context or by commercial players. The 'crowd' can now reinterpret and distribute the original object in as many instances and variations as desired. Ownership of these instances of the object becomes the community's, the 'crowd's'; community ownership as an integral characteristic of cultural heritage.

The Tate licenses some of their digital images of artwork for use for non-commercial and educational purposes under the Creative Commons license CC-BY-NC-ND (attribution - noncommercial - no derivatives). "The aim is to provide a simple, standardized way to grant copyright permission for the use of Tate's intellectual property (its photography) and artists' creative work for specific uses only, whilst safeguarding Tate's own income from its IP in commercial contexts whilst ensuring artists, copyright holders and Tate get credit for their work and are protected by law" (tate.org, retrieved $6 / 1 / 2016)$." The screen grab in figure 6 illustrates the variety of the quality of the posters, painted copies and other digital images of the painting reproduced, many on social media sites, in spite of the Tate's license. Very few of these images give any attribution to the Tate. Deborah Klein's blog, from which the image in figure 2 was copied, gives attribution to both the Tate and the Smallhythe Place collection. Ms. Klein was happy to grant us permission to use the image in this paper.

Figure 6. Images of Sargent's painting of Ellen Terry s Lady Macbeth retrieved online via a Google search.
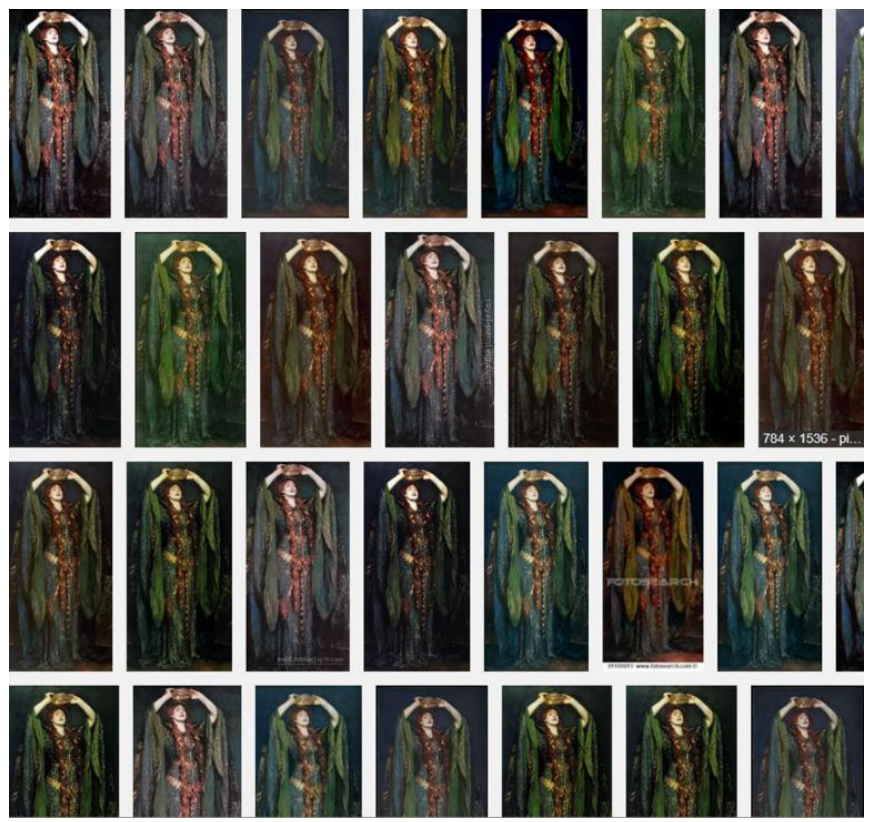

The power of the social networks as distribution platforms and amplifiers for group-based investigations is considerable. (McAllister, 2012). If reproduced with attribution, allowing our images to be copied and distributed increases our audience 
and the value of the original object, and contributes to the knowledge body of cultural heritage. Online images copied from DDM sometimes come with attribution as in the screen grab in figure 7 from the Fashion Spot blog in which the DDM URL (outdated), collection and curators are listed. Images and text from the online gallery created for our exhibition of Geoffrey Beene from the Collection of Iris Barrel Apfel have been faithfully reproduced, but without asking us for right of release. When contacted, The Fashion Blog agreed to update the DDM URL to the current location but responded that they were not responsible for the blog as it resided in their community thread. If we wanted to we could "file a DMCA takedown request with our legal counsel and they will have it removed and warn or ban the member who posted the appropriated content" (The Fashion Spot, 6/21/16). According to Pinterest, this particular DDM gallery has been reproduced on 49 boards. This is one designer, one exhibition, from our archive. In this age of myriad social media, policing the internet for unauthorized, exponentially increasing reproductions while trying to promote a culture of participation, is counter-productive to our goal of open access to fashion design collections and exhibitions for scholarly research and enjoyment by the general public. The DDM team is now deliberating which Creative Commons license to incorporate.

Figure 7. Geoffrey Beene gallery, Drexel Digital Museum project. Retrieved from: The Fashion Spot, June 1, 2016.

http://forums.thefashionspot.com/

\section{source: $h$ ttp $J /$ digimuse.cis.drexel.edu/gallery_indexhtm}

"You should check out this link for more of her "Beene collection", I've only posted some of the pics. There's lots more, like detail shots.

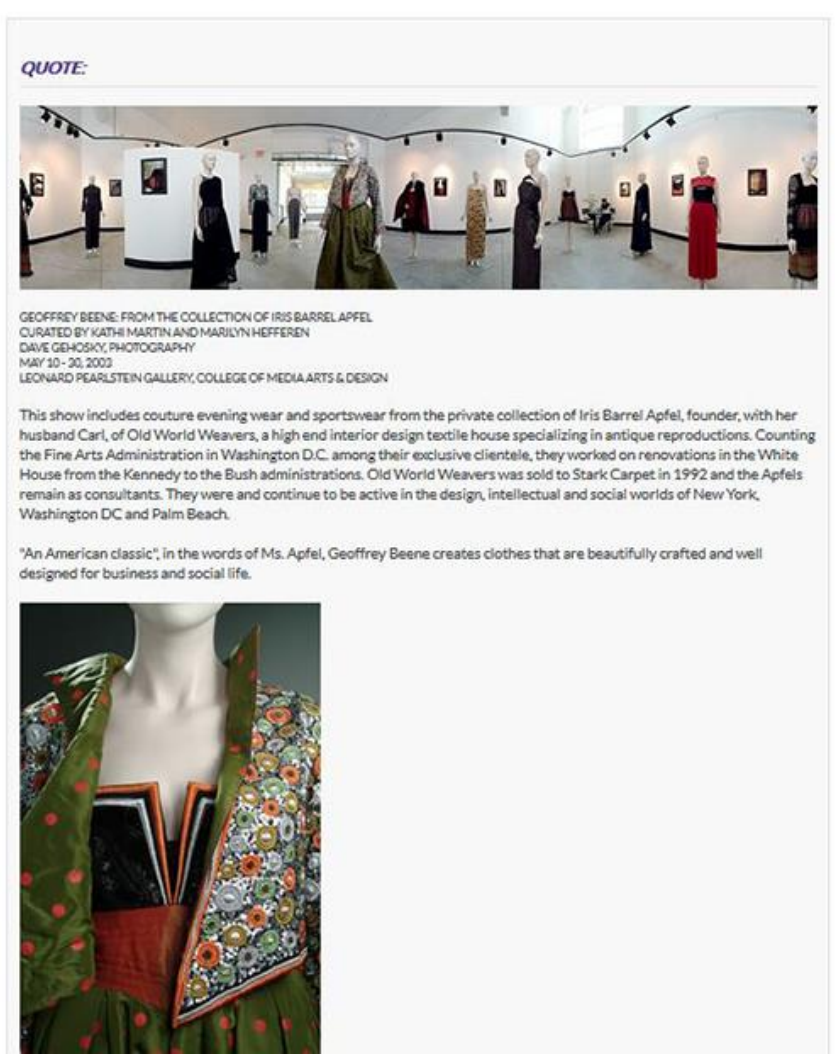

As bandwidth speeds have increased, QTVRs have been replaced with video and Apple has dropped support of QuickTime (Apple, 2014). The DDM has been researching best practices for replacing our QTVR.mov files with 3D Object Virtual Reality (ObjectVR) panoramas and HTML5 to publish interactive panoramas of historic fashion and spaces; and to incorporate evolving metadata standards to manage collections of these artifacts. Our research uses GigaPan technology to create high resolution ObjectVRs; and repurposes the ObjectVRs as web ready HTML5, a developing mark-up language standard for structuring and presenting multi-media and graphic elements online (Applause, 2015). The ObjectVRs can be displayed at up to three times life size, rotated in 360 degree panorama, zoomed into rich detail, and made compatible for the internet via HTML5.(Figures 8,9)

Figure 8. Side, front and back views, evening gown. Thurn, circa 1930. Collection, Object: FHCC. Collection, Image:DDM.

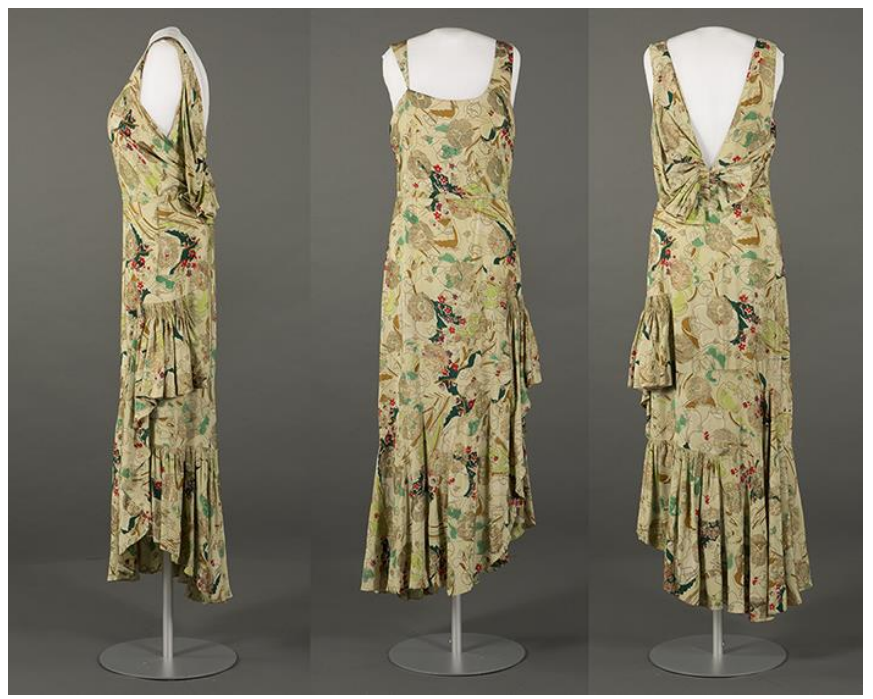

Figure 9. Evening gown. Thurn, circa 1930. Textile detail. Collection, Object: FHCC. Collection, Image:DDM.

\section{Imaging Process Research}




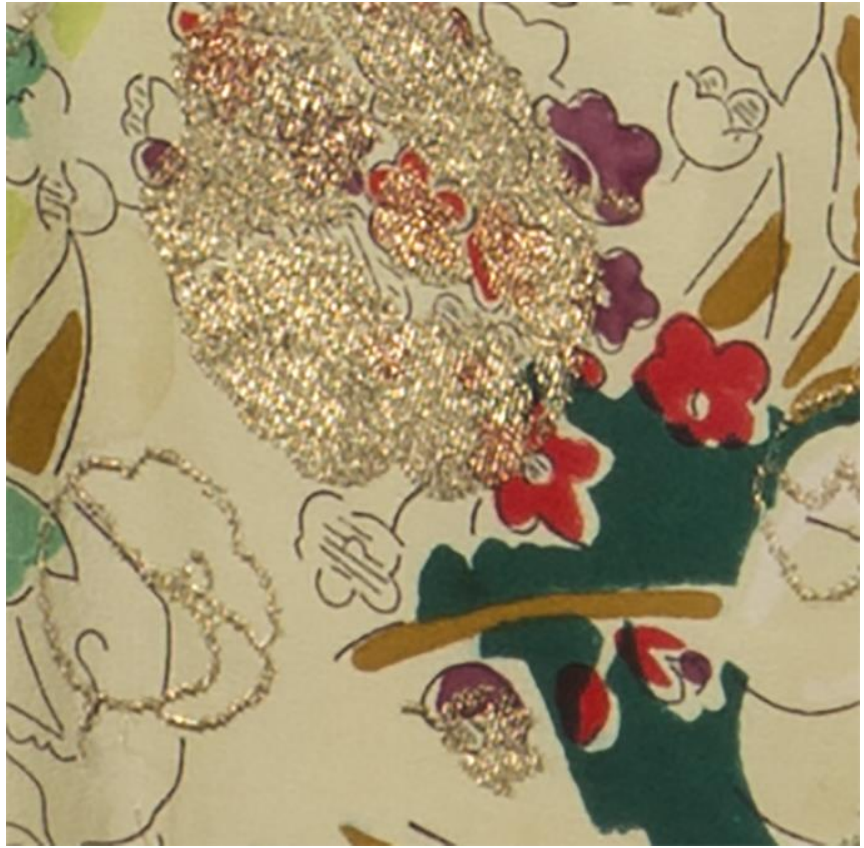

Our foremost responsibility in the image capture process is to confirm the quality and authenticity of the data used to create the facsimile. This requires participation by all disciplines within the team in selection of the object, choice of the best lighting and equipment to enhance detail and maximize resolution (Figures 10,11), and implementation of a semantically based knowledge system, a Metadata Object Description Schema (MODS) mapping for this project, to help to insure perpetual digital discovery and access. Each member brings best practices from their particular discipline and their individual research agenda to form a collective best practices for recording, discovery and conservation of cultural heritage. The entire team becomes the mediator between the object and audience.

Figure 10. DDM equipment/output list.

\begin{tabular}{|c|c|}
\hline \multicolumn{2}{|c|}{ Imaging Equipment Drexel Digital Museum Project } \\
\hline Hardware & File Output \\
\hline $\begin{array}{l}\text { Kaidon Meridian MT- } 84 \text { Motorized Object } \\
\text { Turntable }\end{array}$ & N/A \\
\hline $\begin{array}{l}\text { Canon EOS-1D Mark IV, Lens } 70-200 \mathrm{~mm} \\
\text { f/ } 2.8 \text { camera with GigaPan EPIC Pro Robotic } \\
\text { Camera Mount }\end{array}$ & $\begin{array}{l}\text { Camera Raw Image (.CR2), } 48 \text { bit RGB, } 15.9 \\
\text { megapixel: } 4896 \times 3264 \text { pixels }-3 \text { columns of } 12 \\
\text { rows }=36 \text { images per view * } 18 \text { views }=648 \\
\text { images per garment }\end{array}$ \\
\hline $\begin{array}{l}\text { Canon EOS 5D Mark II. Lens } 24-105 \mathrm{~mm} \mathrm{f} / 4 \\
\text { Camera, stationary }\end{array}$ & $\begin{array}{l}\text { Camera Raw Image, Native, full color resolution, } \\
21 \text { megapixel: } 3744 \times 5616,1 \text { full length image for } \\
\text { each view }\end{array}$ \\
\hline \multicolumn{2}{|l|}{$\begin{array}{l}\text { Color Calibrator Chart: X-Rite Color } \\
\text { Checker Passport }\end{array}$} \\
\hline \multicolumn{2}{|l|}{ Software } \\
\hline Adobe Photoshop Creative Cloud 2015 & TIF, 230.7 megapixel, 32 bit RGB, $11190 \times 20620$ \\
\hline PTGui Pro & TIF, 316.5 megapixel, 32 bit RGB, $15354 \times 20620$ \\
\hline \multirow[t]{5}{*}{ Object2VR Garden Gnome Software } & Images/tiles folder \\
\hline & - XML \\
\hline & - HTML \\
\hline & - Javascript player \\
\hline & - Javascript file for the skin \\
\hline
\end{tabular}

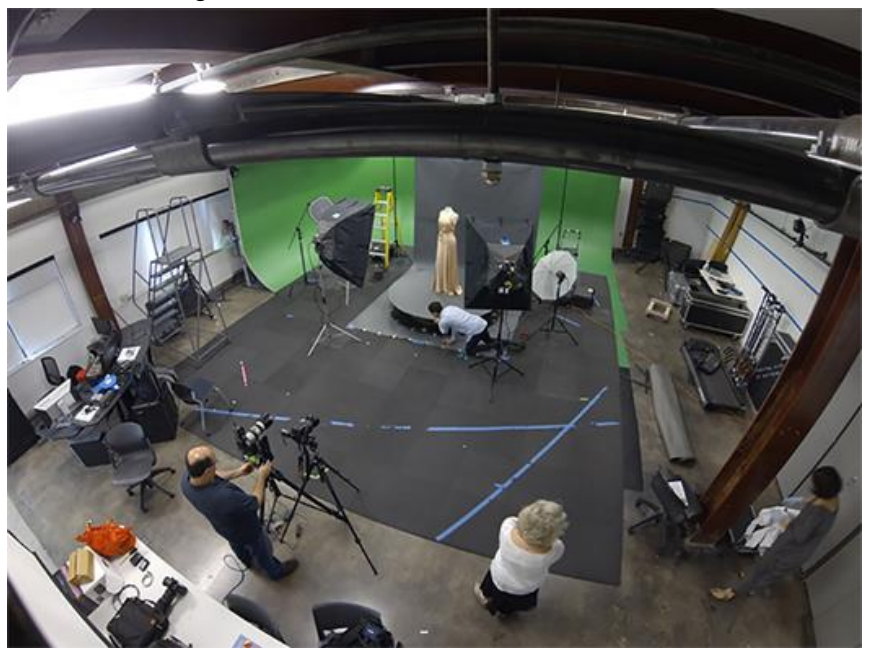

Google Docs, the digimuse website and external hard drives exchanged via post provide the platform for our international collective investigations. Drexel University Libraries team has developed a strategy to provide description and discovery of the DDM's research objects across multiple platforms through their Islandora based University's iDEA repository, iDEA. Persistent Uniform Resource Locators (PURLS) generated by the iDEA repository (Handles) as well as the Libraries' subscription to the EZID service from the California Digital Library, will permanently connect the ObjectVR with the related data sets in iDEA. The PURLS will also be useful in our future goal to eventually expose this collection as linked open data, a best practice for exposing, sharing, and connecting pieces of data, information, and knowledge on the Semantic Web. (LODLAM, 2016).

\section{Exhibiting New Fashion Media}

Dressing, shipping, insuring, and preparing for display of original historic fashion objects is expensive. These finite objects will deteriorate with each additional exhibition. Our high resolution, interactive ObjectVRs record the original object at that moment in time, before further deterioration. The HTML 5 file of the gown in figure 12 can be viewed here: http://digimuse2.westphal.drexel.edu/DDMFranklinTurnerJes sie03/.

Figure 12. Side, front and back views, ObjectVR, evening gown. Jessie Franklin Turner, circa 1930. Collection, Object: FHCC. Collection, Image: DDM.

Figure 11. DDM imaging session. 


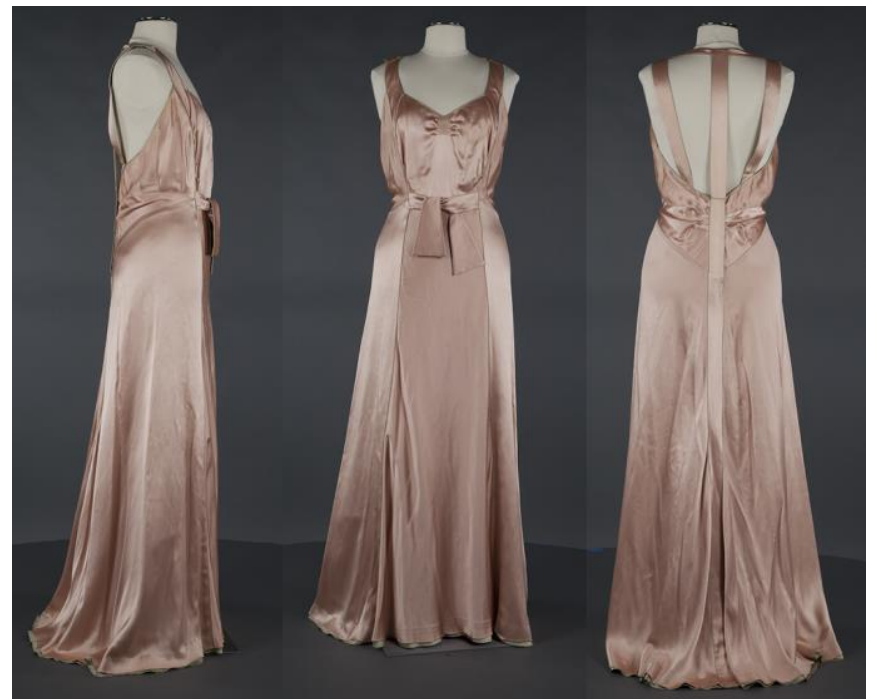

The team plans to integrate the ObjectVRs into 3D panoramas of historic spaces and exhibit them in high resolution, large scale display in future exhibitions. Using an $\mathrm{iPad}$, the audience will be able to rotate the garment to all sides, zoom in on details and access linked data from other repositories. The digital museum can be loaded onto a hard drive and shipped around the world, scaled up for exhibition on 12 foot monitors or scaled down for 24 inch monitors. The ObjectVRs can be combined with digital artifacts and 3D panoramas of other historic spaces to create additional perspectives and new interpretations of our collective cultural heritage (Figure 13).

Figure 13. 3D panorama, Drexel Picture Gallery, Drexel University.

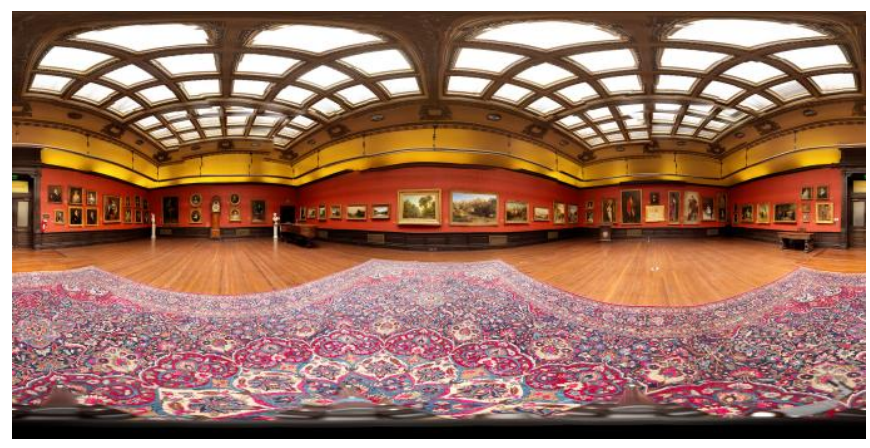

\section{Conclusion}

Heritage artifacts carry historic knowledge. Technology can foster a participatory learning culture where the user creates personal meaning from the artifact rather than passively accept what is directed by curators and educators (Bautista, 2014; Hein, 1995). Exhibition visitors' ability to interact directly with the digital heritage artifact takes them from a reactive museum experience to active participation in the distributed exhibition, customizing and re-contextualizing their encounter with each object and giving the visitor agency in their experience of fashion. For the most egalitarian dissemination, our digital artifacts are being repurposed for the internet, where they can be freely and inexpensively shared, numerous times, with a varied audience, singularly or in concert with friends and/or strangers, without harm to the original object.

McAllister reminds us that collaboration in and of itself is not interesting as an objective. Successful collaborations involve "a high level of openness in the system, authoritative advocates and demonstrable leadership among them at least on a part-time basis, repeatability when successes appear and efficient ways to share learnings, and strong signals to participate spreading far and wide (2012)." Through the iDEA repository we will openly share all files and processes used to create the ObjectVRs with scholars and researchers of historic fashion and new media in the 'crowd'. We encourage their experiments and re-combinations of our digital heritage objects and share Lowe's observation that copies of an original can allow the viewer to witness "the many layers of its past including ... its present state and even perhaps anticipating how the object will be interpreted in the future" by the 'crowd' (2015).

\section{Acknowledgments}

We thank Holly Tomren, Spencer Lamm and the members of the Drexel University Library's iDEA team for their collaboration in mapping the metadata schema of the DDM to the Metadata Object Description Schema (MODS) standards; and Deborah Morley, Director, Data \& Digital Stewardship and Danuta Niteki, Dean, the Drexel University Libraries, Allen Sabinson, Dean of the Westphal College and Roberta Gruber, Director of the Department of Design, for their support of the project.

\section{References}

Arnold, R. (2002). Looking American: Louise Dahl-Wolfe's Fashion Photographs of the 1930s and 1940s. Fashion Theory, Volume 6, Issue 1, United Kingdom: Berg. 2002, p. 45, 49.

Bautista, Susan (2014) Museums in the Digital Age. United Kingdom: Altimira Press.

CC0 "No Rights Reserved". Retrieved from: https://creativecommons.org/about/cc0/

Creative Commons licences (sic) and Tate. Retrieved from: http://www.tate.org.uk/about/who-we-are/policies-andprocedures/website-terms-use/copyright-andpermissions/creative-commons

Ellen Terry, John Singer Sargent and the Beetle Dress. (2015). Retrieved from: http://deborahklein.blogspot.com/2015/03/ellenterry-john-singer-sargent-and.html

Hein, G. (1995). The Constructivist Museum. Journal for Education in Museums No. 16, 21-23. Retrieved from: http://www.gem.org.uk/pubs/news/hein1995.php

Hollander, A. (1973) Seeing through Clothes. Berkeley: University of California Press, 311.

Iris Barrel Apfel. Retrieved from: http://forums.thefashionspot.com/f81/iris-barrel-apfel-32471.html

Kennedy, M. (2011). Ellen Terry's beetlewing gown back in limelight after $£ 110,000$ restoration. 11 March. Retrieved from: 
SIGraDi 2016, XX Congress of the Iberoamerican Society of Digital Graphics

9-11, November, 2016 - Buenos Aires, Argentina

https://www.theguardian.com/culture/2011/mar/11/ellen-terry-

beetlewing-gown-macbeth

Linked Open Data in Libraries, Archives, and Museums. Retrieved from: lodlam.net/about/

McAlister, M. The power of collective research, task-based investigations and swarm intelligence. Inside Online Media.

Retrieved from:

http://www.mattmcalister.com/blog/2012/06/14/1833/the-powerof-collective-research-task-based-investigations-and-swarmintelligence/

Rottenberg, D. (2000) The Man Who Made Wall Street. Philadelphia, PA: The University of Pennsylvania Press, 149-159.

Sattin, A. \& Lowe, A. (2015) Meet the master of reproduction. Christies

Magazine November 9, 2015. Retrieved from: christies.com/features/Master-of-reproduction-Adam-Lowe-andFactum-Arte-6776-1.aspx

Sylvia. 40+Plus. Style icon Iris Apfel. Retrieved from: 40plusstyle.com/style-icon-iris-apfel/

The call to kill Adobe's Flash in favor of HTML5 is rising. Retrieved from arc.applause.com/2015/07/14/flash-vulnerability-html5replacement/

The Drexel Digital Museum Project (under construction) http://digimuse.westphal.drexel.edu

U.S. National Archives and Records Administration (NARA): Technical

Guidelines for Digitizing Archival Materials for Electronic Access: Creation of Production Master Files - Raster Images. (2004). Retrieved

from: archives.gov/preservation/technical/guidelines.html

Verwayen, H.,Arnoldis, M. \& Kaufman, P. The Problem of the Yellow Milkmaid, A Business Model Perspective on Open Metadata. Retrieved

from:

http://pro.europeana.eu/files/Europeana Professional/

Publications/Whitepaper 2-The Yellow Milkmaid.pdf

Wellington, E. (2007) philly.com. Toby Lerner passes the baton. Posted: January 07, 2007.Retrieved from: articles.philly.com/2007-01-07/news/25221309 1 european-

designers-fashion-boutique 